\title{
TORQUe RipPle Minimization OF MATRIX CONVERTER-FED PMSM DRIVES USING ADVANCED DIRECT TORQUE CONTROL
}

\author{
S.Kannan $^{1}$, S.Chinnaiya ${ }^{2}$ and S.U.Prabha ${ }^{3}$ \\ 1, 2 Department of Electrical and Electronics Engineering, K.S.R. College of Engineering \\ Tiruchengode, India \\ 3 Department of Electrical and Electronics Engineering, Sri Ramakrishna Engineering \\ College,Coimbatore, India
}

\begin{abstract}
An advanced direct torque control (DTC) technique using Model predictive control (MPC) is proposed for matrix converter (MC)-based permanent-magnet synchronous motor (PMSM) drive system, which reduces the torque ripples, does not need the duty cycle calculation, and ensures the fixed switching frequency. Analytical expressions of change rates of torque and flux of PMSM as a function of MC-dqo components are derived. The predictive model of PMSM and MC is realized by means of State model. Then, the advanced MC-fed DTC algorithm is implemented based on Cost function evaluation. The simulation results exhibit remarkable torque ripple reduction with the help of MPC. As a result, the proposed strategy is proved to be effective in minimizing the torque ripples for MC-based PMSM drives.
\end{abstract}

\section{Keywords}

Direct torque control (DTC), matrix converter (MC), permanent-magnet synchronous motor (PMSM), Model predictive control (MPC), and Cost function

\section{INTRODUCTION}

The Matrix converter is a single-stage power converter, which consists of $\mathrm{m} \times \mathrm{n}$ bidirectional power switches in an array form. The bidirectional switches in the converter are composed by means of two IGBTs and two diodes connected in anti-parallel. Generally, the number of input phases, $\mathrm{m}$ must be at least three, and the number of output phases, $\mathrm{n}$ can be chosen from one to infinity. Currently, research works on commutation techniques [1], operation stability [2], and control/modulation strategy [4]-[12] of MCs increase the usage of Matrix converter in many fields like elevators, wind power generation, and mechanical manufacture [13].

A tremendous research work focusing on control and modulation strategies of MCs can be divided into four types. They are scalar techniques, pulse width modulation (PWM), predictive control, and direct torque control (DTC) [3].The Venturini method [4] is the first scalar technique, which obtains the duty ratio of each switch directly by calculating the function of the instantaneous value of the input voltage and the reference value of the output voltage. The Space vector modulation [5] (SVM) is based on the instantaneous space vector representation of input and output voltages and currents and it exploits the pulse width modulation, which was developed and improved in the 1990s. The modern technique, predictive control [6], [7] evaluates the effect DOI : 10.14810/ijscmc.2014.3404 
of each possible switching state by a cost function. The switching state which minimizes the cost function will be selected to output. The DTC exploits the hysteresis comparators and SVM switching tables to obtain high-performance ac drives, was extended to MC-fed induction machines (MC-DTC) in 2001 [8]. Normally, MC-DTC adopts hysteresis comparators and switching tables which experiences the two major shortcomings: significant torque ripples and variable switching frequency [14]. To overcome these drawbacks, [15] is implemented which utilizes the duty cycle calculation. Since it reduces the torque ripples up to $30 \%$, it has some disadvantages:

- It uses multilevel hysteresis and subdivided voltage vectors to reduce torque ripple.

- Discrete SVM should be produced to obtain 56 virtual voltage vectors with different amplitude.

- Formation of switching table is offline \& requires more accurate calculation.

- Exploits the duty cycle control.

- Complicated to implement \&depends on motor parameters.

To avoid all these drawbacks an advanced DTC technique is proposed in this paper.

- The Model predictive control strategy is implemented with the MC - DTC fed PMSM motor to minimize the torque ripples.

- The generalized MP-DTC [16] is approached to reduce the switching losses.

- The Branch and Bound algorithm [17] for PMSM is carried out to reduce the computational time of Cost function.

\section{MC-DTC TOPOLOGY}

\subsection{Principle of Matrix converter}

The matrix converter having 9 bi-directional switches that allow any output phase to be connected to any input phase. The circuit configuration is shown in Fig.1. The input terminals of the converter are connected to a three phase power supply, while the output terminal are connected to a three phase load, like an induction motor. The relationship between the input and output voltage and current of MC can be expressed as

$$
\left(\begin{array}{c}
v_{a} \\
v_{b} \\
v_{c}
\end{array}\right)=\left(\begin{array}{lll}
S_{A a}(t) & S_{A b}(t) & S_{A c}(t) \\
S_{B a}(t) & S_{B b}(t) & S_{B c}(t) \\
S_{C a}(t) & S_{C b}(t) & S_{C c}(t)
\end{array}\right)\left(\begin{array}{c}
v_{A} \\
v_{B} \\
v_{C}
\end{array}\right)=M \cdot v_{i}
$$

and

$$
\left(\begin{array}{l}
i_{a} \\
i_{b} \\
i_{c}
\end{array}\right)=\left(\begin{array}{lll}
S_{A a}(t) & S_{B a}(t) & S_{C a}(t) \\
S_{A b}(t) & S_{B b}(t) & S_{C b}(t) \\
S_{A c}(t) & S_{B c}(t) & S_{C c}(t)
\end{array}\right)\left(\begin{array}{c}
i_{A} \\
i_{B} \\
i_{C}
\end{array}\right)=M^{T} . i_{o}
$$

where $s_{p q}(t)$ is the state of switch $\mathrm{S}_{p q}, \mathrm{p} \in\{\mathrm{A}, \mathrm{B}, \mathrm{C}\}, \mathrm{q} \in\{\mathrm{a}, \mathrm{b}, \mathrm{c}\}$, and $\boldsymbol{M}^{\mathrm{T}}$ is the transpose of transfer matrix $\boldsymbol{M}$. Theoretically, the nine bi-directional switches of the matrix converter can assume $512\left(2^{9}\right)$ different switching states . But all of them cannot be employed usefully. 
Irrespective to the control method of the matrix converter, the choice of switching states combinations must obey with two basic rules.

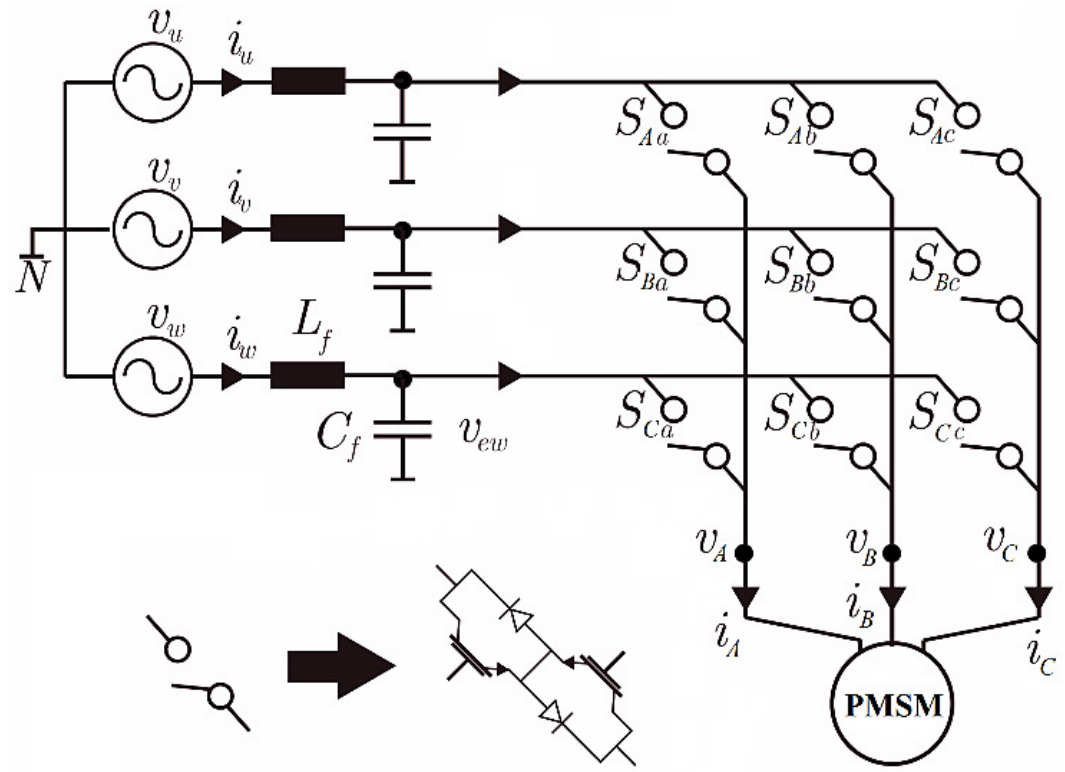

Fig. 1. Schematic representation of a matrix converter.

If the converter is supplied by a voltage source and feeds an inductive load, the input phases should never be short-circuited and the output currents should not be interrupted. From a practical point of view these rules imply that one and only one bi-directional switch per output phase must be switched on at any instant. Because of this oblige, the matrix converter can follow 27 switching combinations only.

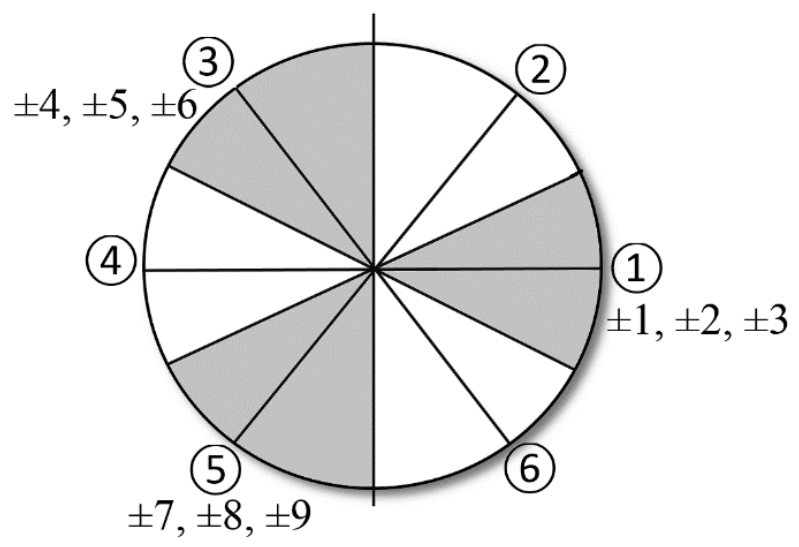

Fig. 2. Output line-to-neutral voltage vector configuration

In the 27 successive switching states, only 21 can be practically exploited in the DTC algorithm. These configurations are presented in Table 1. The first 18 switching configurations have the same feature of connecting two output phases to the same input phase. The corresponding output line-to-neutral voltage vector and input line current vector, have fixed directions, as represented 
in Figs. 2 and 3, and will be named "active configurations." The magnitude of these vectors depends upon the instantaneous values of the input line-to-neutral voltages and output line currents respectively as shown in Table 1 . Three switching configurations regulate zero input current and output voltage vectors and will be named "zero configurations." The remaining six switching configurations have the three output phases connected to a different input phase.

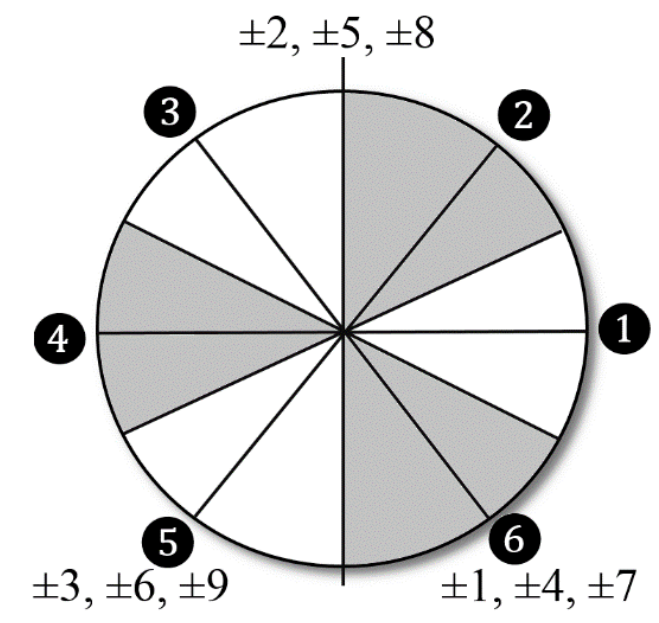

Fig. 3. Input line current vector configuration

\subsection{Existing MC-DTC}

Normally, the VSI-DTC employs one switching state from the VSI switching table during one sampling period to increase or decrease motor torque or flux [18]. The output voltage vectors of MC have the same direction as those delivered by a VSI $\left(\boldsymbol{V}_{1}-\boldsymbol{V}_{6}\right)$, as shown in Fig. 2. Hence, MC-DTC based on VSI-DTC can adjust the input power factor on the grid side and torque and flux on the motor side at the same time, by means of the second selection of switching states. In Fig. 2, the space is equally divided into six sectors, which are indexed by $h_{\alpha}(\alpha=1,2, \ldots, 6)$, with the first sector covering from $-\pi / 6$ to $\pi / 6$. As a result, in each sector, there are two output voltage vectors that have the same direction as that of the VSI vector, and their related input current vectors just lie on different sides of the input voltage vector, in which way the phase between input voltages and currents could be controlled.

The schematic diagram of the Existing MC-DTC [15] is presented in Fig. 4. One desired virtual VSI voltage vector is selected from the VSI switching table (see Table 2). Then, one MC switching state is employed [15] from Table 3 based on the virtual VSI voltage vector. When a zero-voltage vector is required from Table 2 , the zero configuration of the $\mathrm{MC}$, which minimizes the number of commutations, is selected. The torque and flux are estimated, as shown in the lower part of Fig. 4, in which the required output voltage and input current can be obtained from the input voltage, output current, and transfer matrix $\boldsymbol{M}$.

\subsection{Duty cycle calculation}

It can be seen that an enhanced switching table and a duty cycle calculation part are added based on the standard method as shown in fig. 4. At first, an active voltage vector is chosen using the 
standard method; then, $p_{\tau}$ is obtained by referring to the enhanced switching table. At last, the duty cycle is calculated by substituting $p_{\tau}$ and motor speed as,

$d=\frac{\Delta T_{e}}{K_{T p_{\tau}}}+\frac{p_{e}}{p_{\tau}}$

As the online calculation of the functions of $\tau$ and $\lambda$ according to Table 1 will bring undesirable calculation burden, a lookup table with the average values of $\tau$ and $\lambda$ can eliminate the burden by explicitly showing the effects of MCs voltage vectors on torque and flux.It can be seen from

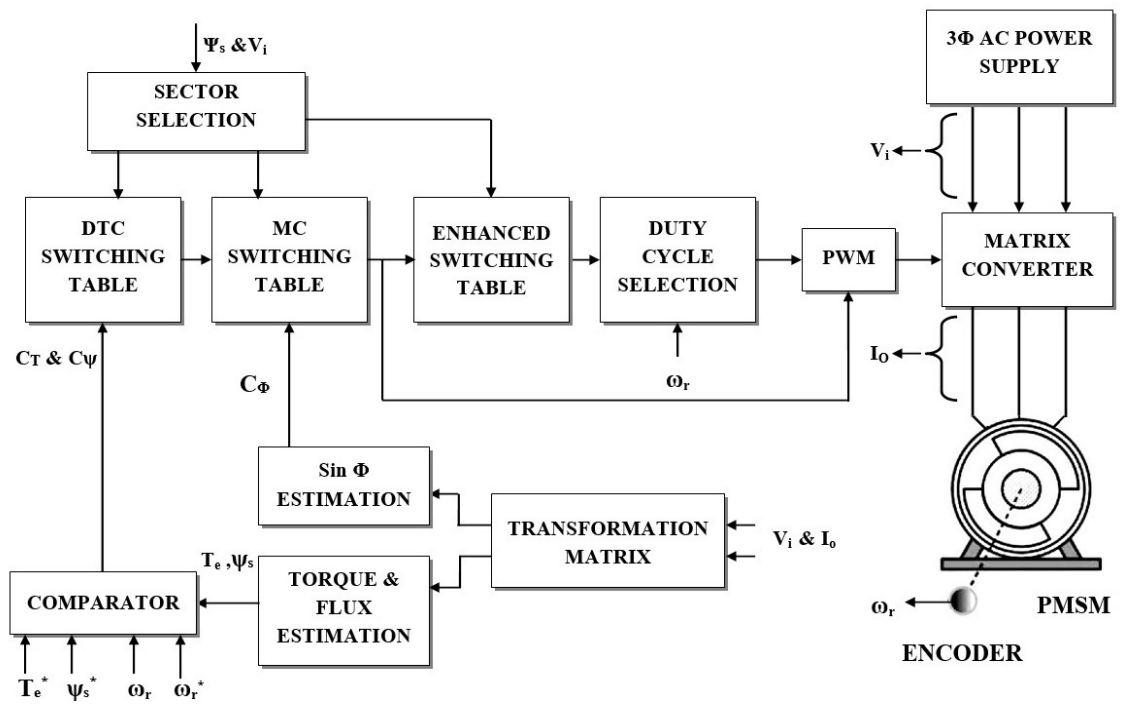

Fig. 4. Block diagram of existing MC-DTC

Table 1 that the functions of $\tau$ and $\lambda$ of all switching states are obtained by multiplying the two terms. 
International Journal of Soft Computing, Mathematics and Control (IJSCMC), Vol. 3, No. 4, November 2014

Table 1. Switching configurations used in MC-DTC scheme

\begin{tabular}{|c|c|c|c|c|c|c|c|}
\hline \multirow{3}{*}{$\begin{array}{c}\text { MC } \\
\text { State } \\
+1 \\
\end{array}$} & \multirow{2}{*}{\multicolumn{3}{|c|}{ Switches }} & \multicolumn{2}{|c|}{ Output } & \multicolumn{2}{|c|}{ Input } \\
\hline & & & & \multirow{2}{*}{$\frac{\mathrm{V}_{\mathrm{o}}}{2 / 3 \mathrm{v}_{\mathrm{ab}}}$} & \multirow{2}{*}{$\begin{array}{c}\alpha_{o} \\
0 \\
\end{array}$} & \multirow{2}{*}{$\frac{\mathrm{I}_{\mathrm{i}}}{2 / \sqrt{3} \mathrm{i}_{\mathrm{A}}}$} & \multirow{2}{*}{$\begin{array}{c}\beta_{\mathrm{i}} \\
-\pi / 6 \\
\end{array}$} \\
\hline & $\mathrm{S}_{\mathrm{Aa}}$ & $\mathrm{S}_{\mathrm{Bb}}$ & $\mathrm{S}_{\mathrm{Cb}}$ & & & & \\
\hline-1 & $\mathrm{~S}_{\mathrm{Ab}}$ & $\mathrm{S}_{\mathrm{Ba}}$ & $\mathrm{S}_{\mathrm{Ca}}$ & $-2 / 3 v_{a b}$ & 0 & $-2 / \sqrt{3} i_{A}$ & $-\pi / 6$ \\
\hline+2 & $\mathrm{~S}_{\mathrm{Ab}}$ & $\mathrm{S}_{\mathrm{Bc}}$ & $\mathrm{S}_{\mathrm{Cc}}$ & $2 / 3 v_{b c}$ & 0 & $2 / \sqrt{3} i_{A}$ & $\pi / 2$ \\
\hline-2 & $\mathrm{~S}_{\mathrm{Ac}}$ & $\mathrm{S}_{\mathrm{Bb}}$ & $\mathrm{S}_{\mathrm{Cb}}$ & $-2 / 3 v_{b c}$ & 0 & $-2 / \sqrt{3} i_{A}$ & $\pi / 2$ \\
\hline+3 & $\mathrm{~S}_{\mathrm{Ac}}$ & $\mathrm{S}_{\mathrm{Ba}}$ & $\mathrm{S}_{\mathrm{Ca}}$ & $2 / 3 v_{\mathrm{ca}}$ & 0 & $2 / \sqrt{3} i_{A}$ & $7 \pi / 6$ \\
\hline-3 & $\mathrm{~S}_{\mathrm{Aa}}$ & $\mathrm{S}_{\mathrm{Bc}}$ & $\mathrm{S}_{\mathrm{Cc}}$ & $-2 / 3 v_{c a}$ & 0 & $-2 / \sqrt{3} i_{A}$ & $7 \pi / 6$ \\
\hline+4 & $\mathrm{~S}_{\mathrm{Ab}}$ & $\mathrm{S}_{\mathrm{Ba}}$ & $\mathrm{S}_{\mathrm{Cb}}$ & $2 / 3 v_{a b}$ & $2 \pi / 3$ & $2 / \sqrt{3} i_{B}$ & $-\pi / 6$ \\
\hline-4 & $\mathrm{~S}_{\mathrm{Aa}}$ & $\mathrm{S}_{\mathrm{Bb}}$ & $\mathrm{S}_{\mathrm{Ca}}$ & $-2 / 3 v_{a b}$ & $2 \pi / 3$ & $-2 / \sqrt{ } 3 i_{B}$ & $-\pi / 6$ \\
\hline+5 & $\mathrm{~S}_{\mathrm{Ac}}$ & $\mathrm{S}_{\mathrm{Bb}}$ & $\mathrm{S}_{\mathrm{Cc}}$ & $2 / 3 v_{b c}$ & $2 \pi / 3$ & $2 / \sqrt{3} i_{B}$ & $\pi / 2$ \\
\hline-5 & $\mathrm{~S}_{\mathrm{Ab}}$ & $\mathrm{S}_{\mathrm{Bc}}$ & $\mathrm{S}_{\mathrm{Cb}}$ & $-2 / 3 v_{b c}$ & $2 \pi / 3$ & $-2 / \sqrt{3} i_{B}$ & $\pi / 2$ \\
\hline+6 & $\mathrm{~S}_{\mathrm{Aa}}$ & $\mathrm{S}_{\mathrm{Bc}}$ & $\mathrm{S}_{\mathrm{Ca}}$ & $2 / 3 \mathrm{v}_{\mathrm{ca}}$ & $2 \pi / 3$ & $2 / \sqrt{3} i_{B}$ & $7 \pi / 6$ \\
\hline-6 & $\mathrm{~S}_{\mathrm{Ac}}$ & $\mathrm{S}_{\mathrm{Ba}}$ & $\mathrm{S}_{\mathrm{Cc}}$ & $-2 / 3 v_{c a}$ & $2 \pi / 3$ & $-2 / \sqrt{3} i_{B}$ & $7 \pi / 6$ \\
\hline+7 & $\mathrm{~S}_{\mathrm{Ab}}$ & $\mathrm{S}_{\mathrm{Bb}}$ & $\mathrm{S}_{\mathrm{Ca}}$ & $2 / 3 v_{a b}$ & $4 \pi / 3$ & $2 / \sqrt{3} \mathrm{i}_{\mathrm{C}}$ & $-\pi / 6$ \\
\hline-7 & $\mathrm{~S}_{\mathrm{Aa}}$ & $\mathrm{S}_{\mathrm{Ba}}$ & $\mathrm{S}_{\mathrm{Cb}}$ & $-2 / 3 v_{a b}$ & $4 \pi / 3$ & $-2 / \sqrt{3} i_{C}$ & $-\pi / 6$ \\
\hline+8 & $\mathrm{~S}_{\mathrm{Ac}}$ & $\mathrm{S}_{\mathrm{Bc}}$ & $\mathrm{S}_{\mathrm{Cb}}$ & $2 / 3 v_{b c}$ & $4 \pi / 3$ & $2 / \sqrt{3} \mathrm{i}_{\mathrm{C}}$ & $\pi / 2$ \\
\hline-8 & $\mathrm{~S}_{\mathrm{Ab}}$ & $\mathrm{S}_{\mathrm{Bb}}$ & $\mathrm{S}_{\mathrm{Cc}}$ & $-2 / 3 v_{b c}$ & $4 \pi / 3$ & $-2 / \sqrt{3} i_{C}$ & $\pi / 2$ \\
\hline+9 & $\mathrm{~S}_{\mathrm{Aa}}$ & $\mathrm{S}_{\mathrm{Ba}}$ & $\mathrm{S}_{\mathrm{Cc}}$ & $2 / 3 v_{\mathrm{ca}}$ & $4 \pi / 3$ & $2 / \sqrt{ } 3 \mathrm{i}_{\mathrm{C}}$ & $7 \pi / 6$ \\
\hline-9 & $\mathrm{~S}_{\mathrm{Ac}}$ & $\mathrm{S}_{\mathrm{Bc}}$ & $\mathrm{S}_{\mathrm{Ca}}$ & $-2 / 3 v_{c a}$ & $4 \pi / 3$ & $-2 / \sqrt{3} i_{C}$ & $7 \pi / 6$ \\
\hline $0_{\mathrm{a}}$ & $\mathrm{S}_{\mathrm{Aa}}$ & $\mathrm{S}_{\mathrm{Ba}}$ & $\mathrm{S}_{\mathrm{Ca}}$ & 0 & - & 0 & - \\
\hline $0_{\mathrm{b}}$ & $\mathrm{S}_{\mathrm{Ab}}$ & $\mathrm{S}_{\mathrm{Bb}}$ & $\mathrm{S}_{\mathrm{Cb}}$ & 0 & - & 0 & - \\
\hline $0_{c}$ & $\mathrm{~S}_{\mathrm{Ac}}$ & $\mathrm{S}_{\mathrm{Bc}}$ & $\mathrm{S}_{\mathrm{Cc}}$ & 0 & - & 0 & - \\
\hline
\end{tabular}

The one containing $\alpha_{\mathrm{i}}$ is related to time, which will be referred to as time-dependent expression in the following sections, and the other containing $\theta_{\mathrm{s}}$ is related to the relative position of the stator flux vector to output voltage vector. The enhanced switching table of all the positive vectors can be obtained by moving the numbers of $l_{\alpha}$ and $l_{\theta}$.

Table 2. VSI switching table

\begin{tabular}{|c|c|c|c|c|c|c|c|}
\hline \multirow{3}{*}{$\mathbf{C}_{\boldsymbol{\psi}}$} & \multirow{2}{*}{$\mathbf{C}_{\mathbf{T}}$} & \multicolumn{6}{|c|}{ Stator Flux Sectors $\mathbf{h}_{\boldsymbol{\theta}}$} \\
\cline { 3 - 8 } & & 1 & 2 & 3 & 4 & 5 & 6 \\
\hline \multirow{4}{*}{+1} & +1 & $\mathrm{~V}_{2}$ & $\mathrm{~V}_{3}$ & $\mathrm{~V}_{4}$ & $\mathrm{~V}_{5}$ & $\mathrm{~V}_{6}$ & $\mathrm{~V}_{1}$ \\
\cline { 2 - 8 } & 0 & $\mathrm{~V}_{7}$ & $\mathrm{~V}_{0}$ & $\mathrm{~V}_{7}$ & $\mathrm{~V}_{0}$ & $\mathrm{~V}_{7}$ & $\mathrm{~V}_{0}$ \\
\cline { 2 - 8 } & -1 & $\mathrm{~V}_{6}$ & $\mathrm{~V}_{1}$ & $\mathrm{~V}_{2}$ & $\mathrm{~V}_{3}$ & $\mathrm{~V}_{4}$ & $\mathrm{~V}_{5}$ \\
\hline \multirow{3}{*}{-1} & +1 & $\mathrm{~V}_{3}$ & $\mathrm{~V}_{4}$ & $\mathrm{~V}_{5}$ & $\mathrm{~V}_{6}$ & $\mathrm{~V}_{1}$ & $\mathrm{~V}_{2}$ \\
\cline { 2 - 8 } & 0 & $\mathrm{~V}_{0}$ & $\mathrm{~V}_{7}$ & $\mathrm{~V}_{0}$ & $\mathrm{~V}_{7}$ & $\mathrm{~V}_{0}$ & $\mathrm{~V}_{7}$ \\
\cline { 2 - 8 } & -1 & $\mathrm{~V}_{5}$ & $\mathrm{~V}_{6}$ & $\mathrm{~V}_{1}$ & $\mathrm{~V}_{2}$ & $\mathrm{~V}_{3}$ & $\mathrm{~V}_{4}$ \\
\hline
\end{tabular}


International Journal of Soft Computing, Mathematics and Control (IJSCMC), Vol. 3, No. 4, November 2014

Table 3. MC switching table

\begin{tabular}{|l|c|c|c|c|c|c|c|}
\hline \multirow{2}{*}{$\mathbf{h}_{\boldsymbol{\alpha}}$} & \multirow{2}{*}{$\mathbf{C}_{\boldsymbol{\varphi}}$} & \multicolumn{7}{|c|}{ VSI Vectors } \\
\cline { 3 - 8 } & & $\mathrm{V}_{1}$ & $\mathrm{~V}_{2}$ & $\mathrm{~V}_{3}$ & $\mathrm{~V}_{4}$ & $\mathrm{~V}_{5}$ & $\mathrm{~V}_{6}$ \\
\hline \multirow{2}{*}{$(1)$} & +1 & -3 & +9 & -6 & +3 & -9 & +6 \\
\cline { 2 - 8 } & -1 & +1 & -7 & +4 & -1 & +7 & -4 \\
\hline \multirow{2}{*}{$(2)$} & +1 & +2 & -8 & +5 & -2 & +8 & -5 \\
\cline { 2 - 8 } & -1 & -3 & +9 & -6 & +3 & -9 & +6 \\
\hline \multirow{2}{*}{$(3)$} & +1 & -1 & +7 & -4 & +1 & -7 & +4 \\
\cline { 2 - 8 } & -1 & +2 & -8 & +5 & -2 & +8 & -5 \\
\hline \multirow{2}{*}{$(4)$} & +1 & +3 & -9 & +6 & -3 & +9 & -6 \\
\cline { 2 - 8 } & -1 & -1 & +7 & -4 & +1 & -7 & +4 \\
\hline \multirow{2}{*}{$(5)$} & +1 & -2 & +8 & -5 & +2 & -8 & +5 \\
\cline { 2 - 8 } & -1 & +3 & -9 & +6 & -3 & +9 & -6 \\
\hline \multirow{2}{*}{ (6) } & +1 & +1 & -7 & +4 & -1 & +7 & -4 \\
\cline { 2 - 8 } & -1 & -2 & +8 & -5 & +2 & -8 & +5 \\
\hline
\end{tabular}

\section{Mathematical Modelling Of PMSM}

In the rotating $d-q$ frame, the dynamics of the surface mounted PMSM is described as [19]

$$
\begin{aligned}
& \frac{d \omega_{r}(t)}{d t}=-\frac{B_{m}}{J_{m}} \omega_{r}(t)+\frac{1}{J_{m}}\left(T_{e}(t)-T_{m}\right) \\
& \frac{d i_{d}(t)}{d t}=-\frac{R_{s}}{L} i_{d}(t)+\omega_{e}(t) i_{d}(t)+\frac{1}{L} v_{d}(t) \\
& \frac{d i_{q}(t)}{d t}=-\frac{R_{s}}{L} i_{q}(t)-\omega_{e}(t) i_{d}(t)-\frac{1}{L} \omega_{e}(t) \lambda_{m}+\frac{1}{L} v_{q}(t)
\end{aligned}
$$

where $\omega_{r}(t)$ is the rotor speed, $\omega_{e}(t)$ is the electrical rotational rotor speed, $i_{d}(t)$ and $i_{q}(t)$ are the stator current in $d-q$ frame, respectively. The electromagnetic torque of PMSM is expressed as [20]

$$
T_{e}=\frac{3 p\left|\psi_{s}\right|}{4 L_{d} L_{q}}\left[2 \psi_{f} L_{q} \sin \delta-\left|\psi_{s}\right|\left(L_{q}-L_{d}\right) \sin 2 \delta\right]
$$

where $\delta$ is the displacement angle between the stator and permanent-magnet flux linkage, $\psi_{\mathrm{f}}$ is the permanent-magnet flux, $L_{\mathrm{d}}$ and $L_{\mathrm{q}}$ are the direct and quadrature stator inductances, respectively, and $p$ is the number of pole pairs. From (7), the change rate of torque can be derived as

$$
\frac{d}{d t} T_{e}=\frac{3 p\left|\psi_{s}\right|}{2 L_{d} L_{q}}\left[\psi_{f} L_{q} \cos \delta-\left|\psi_{s}\right|\left(L_{q}-L_{d}\right) \cos 2 \delta\right] \frac{d \delta}{d t}
$$

The derivative of $\delta$ is given by 
$\frac{d \delta}{d t}=\frac{d\left(\theta_{s}-\theta_{r}\right)}{d t}=\omega_{s}-\omega_{r}$

where $\theta_{\mathrm{s}}$ and $\theta_{\mathrm{r}}$ are the stator and rotor positions, respectively, and $\omega_{\mathrm{r}}$ is the rotor electrical angular velocity.

\section{AdVAnCEd DTC}

In this paper, the generalized DTC scheme with Model Predictive control is approached in Fig.5. Here predictive control consists a model of the whole converter and PMSM in order to predict the system behaviour after a computation period for each possible MC configuration. After that a cost function will be used to determine the configuration which is to be applied for the next computing period.

\subsection{Model Predictive control}

In Model Predictive Control [21], the current control input is attained by solving at each sampling instant an inhibited optimal control problem based on the predictions delivered by an internal model of the controlled process. Generally the optimal control problem is formulated over a finite or infinite horizon. The underlying optimization procedure profits an optimal control sequence which minimizes an objective function. The first control input of this sequence is applied in accordance with the so called receding horizon policy. At the next sampling instant, the control sequence is recomputed over a shifted horizon, thus providing feedback.

\subsection{Receding horizon policy}

The MPC algorithm finds the sequence of optimal input $u(k)$ that satisfies given constraints [22]. From that sequence of optimal input $u(k)$, only the first input is applied to plant for next sampling interval. The whole process is repeated for next samples. This method of optimization of $u$ is known as online optimization. The prediction horizon keeps on shifting towards right after each sample and the size of prediction horizon remains constant as shown in fig. 6. So that this mechanism is termed as receding horizon policy. 


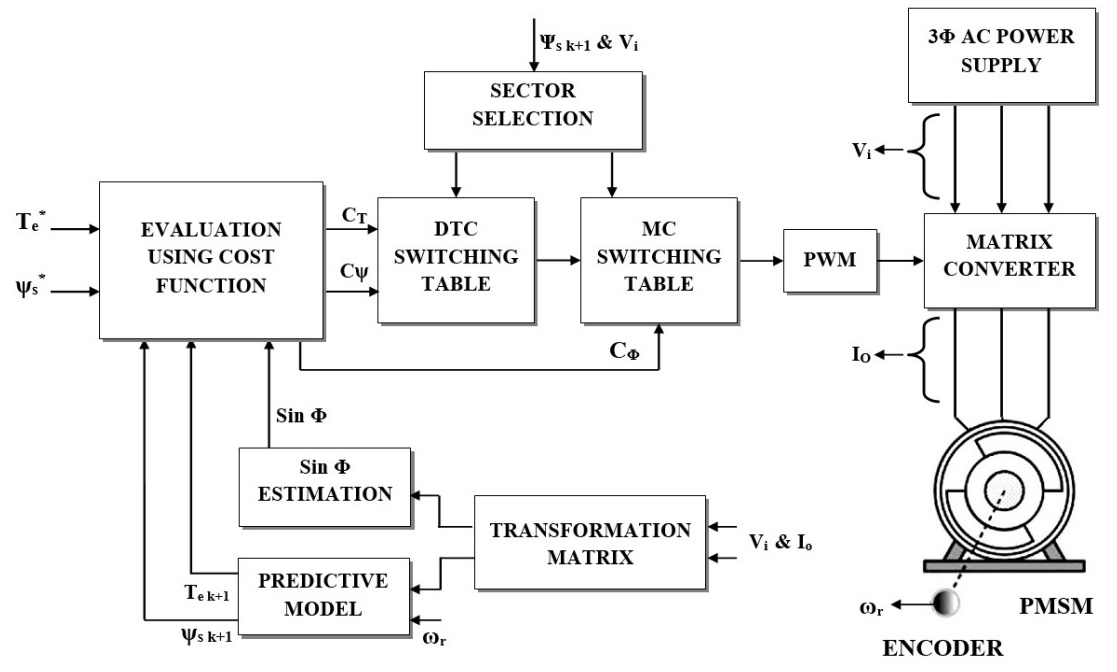

Fig. 5. Block diagram of Advanced MC-DTC.

\subsection{Modelling of MP-DTC scheme}

\subsubsection{Permanent Magnet Synchronous Machine Model}

The PMSM can be modelled with the help of state space equations in the $d q$ rotor frame (10) where $I_{d}, I_{q}$ and $V_{d}, V_{q}$ are stator currents and voltages expressed in the $d q$ frame, $R$ and $L$ are the stator winding resistor and inductance respectively, $\omega$ is the rotor angular speed and $\varphi$ is the flux produced by permanent magnets [22].

$$
\left(\begin{array}{c}
\dot{I}_{d}(t) \\
\dot{I}_{q}(t)
\end{array}\right)=\left(\begin{array}{cc}
-\frac{R}{L} & \omega(t) \\
-\omega(t) & -\frac{R}{L}
\end{array}\right) \cdot\left(\begin{array}{c}
I_{d}(t) \\
I_{q}(t)
\end{array}\right)+\left(\begin{array}{ccc}
\frac{1}{L} & 0 & 0 \\
0 & \frac{1}{L} & -\frac{\omega(t)}{L}
\end{array}\right) \cdot\left(\begin{array}{lll}
V_{d}(t) & V_{q}(t) & \phi)^{t}
\end{array}\right.
$$

The Model parameters $(R, L$ and $\varphi)$ can be considered as constant and rotor electrical speed $(\omega)$ variations can be abandoned for a short sampling period $\mathrm{T}$ of the algorithm. Hence the following model can be found with a first order Euler integration.

$$
\begin{aligned}
& \left(\begin{array}{c}
I_{d}(k+1) \\
I_{q}(k+1)
\end{array}\right)=\left(\begin{array}{cc}
1-\frac{R T}{L} & T \omega(k) \\
-T \omega(k) & 1-\frac{R T}{L}
\end{array}\right) \cdot\left(\begin{array}{c}
I_{d}(k) \\
I_{q}(k)
\end{array}\right)+\left(\begin{array}{cc}
\frac{T}{L} & 0 \\
0 & \frac{T}{L}
\end{array}\right) \cdot\left(\begin{array}{c}
V_{d}(k) \\
V_{q}(k)
\end{array}\right)+\left(\begin{array}{c}
0 \\
-\frac{T \phi}{L} \omega(k)
\end{array}\right) \\
& X(k+1)=A(k) \cdot X(k)+B\left(\begin{array}{c}
V_{d}(k) \\
V_{q}(k)
\end{array}\right)+\Phi(k)
\end{aligned}
$$


where $X(k)=\left[I_{d}(k) I_{q}(k)\right]^{\mathrm{t}} \boldsymbol{B}$ is a constant matrix, and normally $\boldsymbol{A}$ and $\Phi$ depend on rotation speed. $V_{d}, V_{q}$ must be expressed as functions of converter switching states in order to obtain a model of the whole converter - machine.

\subsubsection{Matrix Converter Model}

The dq-voltages $V_{d}$ and $V_{q}$ can be expressed as functions of output voltages $\left[V_{a} V_{b} V_{c}\right]^{t}$ by using rotation matrix as,

$$
\begin{aligned}
& R(\theta(k))=\left(\begin{array}{cc}
\cos (\theta(k)) & \sin (\theta(k)) \\
-\sin (\theta(k)) & \cos (\theta(k))
\end{array}\right) \\
& \left(\begin{array}{c}
V_{d}(k) \\
V_{q}(k)
\end{array}\right)=R(\theta(k)) \cdot \sqrt{\frac{2}{3}}\left(\begin{array}{ccc}
1 & -\frac{1}{2} & -\frac{1}{2} \\
0 & -\frac{\sqrt{3}}{2} & -\frac{\sqrt{3}}{2}
\end{array}\right) \cdot\left(\begin{array}{c}
V_{a}(k) \\
V_{b}(k) \\
V_{c}(k)
\end{array}\right)
\end{aligned}
$$

Also the output voltage can be expressed as function of input voltages with the following intellectual. Let $\lambda_{\kappa}(\lambda=A, B, C$ and $\kappa=a, b, c)$ as the switch between phases $\lambda$ and $\kappa$. Let define $u \lambda_{\kappa}$ as an integer that represent the switch state with the following convention: if $u \lambda_{\kappa}=0$ then the switch $\lambda_{\kappa}$ is open; if $u \lambda_{\kappa}=1$ then the switch $\lambda_{\kappa}$ is closed. In a matrix converter, between the three switches connected to an output phase, one and only one switch can be closed. Certainly if more than one switch is closed, there will be a short circuit of the voltage supply and if none is closed, there is no path for the output phase current. For example, for the phase $a$, this lead to

$$
u_{A a}+u_{B a}+u_{C a}=1
$$

and

$$
\begin{aligned}
& u_{A a}=1 \rightarrow V_{a}=V_{A} \\
& u_{B a}=1 \rightarrow V_{a}=V_{B} \\
& u_{C a}=1 \rightarrow V_{a}=V_{C}
\end{aligned}
$$

Then

$$
V_{a}=u_{A a} V_{A}+u_{B a} V_{B}+u_{C a} V_{C}
$$

As a result output voltages can be expressed as function of input voltages with (18).

$$
\left(\begin{array}{c}
V_{a}(k) \\
V_{b}(k) \\
V_{c}(k)
\end{array}\right)=\left(\begin{array}{lll}
u_{A a}(k) & u_{B a}(k) & u_{C a}(k) \\
u_{A b}(k) & u_{B b}(k) & u_{C b}(k) \\
u_{A c}(k) & u_{B b}(k) & u_{C c}(k)
\end{array}\right) \cdot\left(\begin{array}{c}
V_{A}(k) \\
V_{B}(k) \\
V_{C}(k)
\end{array}\right)
$$


Also the Eqn (15) can be written for phase $b$ and $c$; by the way there are 27 allowable switching configurations for a three-phase to three-phase matrix converter. These converter configurations can be divided into three groups. In the first one, each output phase is connected to a different input phase (e.g. $u_{A a}=u_{B b}=u_{C C}=1$ ). The corresponding output voltage vectors (in the $\alpha \beta$ stator frame) have a constant amplitude and a variable direction. There is six configurations in this group. In the second group, each output phase is connected to the same input phase (e.g. $u_{A a}=u_{B b}$ $\left.=u_{C c}=1\right)$ There is three configurations in this group. They lead to a null output voltage vector.

Finally the eighteen other configurations are in the third group. Two outputs are connected to the same input (e.g. $u_{A a}=u_{B b}=u_{C c}=1$ ). The corresponding output voltage vectors (in the $\alpha \beta$ stator frame) have a constant direction and a variable amplitude. It is worth to note that, for each paper cited in reference, the six configurations from the first group are not considered. Predictive control can use these configurations.

\subsubsection{Model of the whole converter - machine}

Firstly with (1), (2) and (18), if output currents, input voltages $\left(V_{\text {in }}=\left[V_{A} V_{B} V_{c}\right]^{\mathrm{T}}\right)$, angular position and speed are measured, it is possible to predict every possible state vector after a sampling period $X_{n}(k+1)(1 \leq n \leq 27)$ for each possible converter configuration $\boldsymbol{U}_{n}(19)$.

$$
X_{n}(k+1)=A(k) \cdot X(k)+B \cdot R(\theta(k)) \cdot C \cdot U_{n}(k) \cdot V_{\text {in }}(k)+\Phi(k)
$$

Secondly as it is possible to achieve for currents a similar reasoning than the one used to demonstrate (18), it is also possible to predict input currents in a fixed frame $A B$ after a sampling period for each converter configuration (20).

$$
\left.\begin{array}{r}
I_{A n}(k+1) \\
I_{B n}(k+1)
\end{array}\right)=\frac{2}{3}\left(\begin{array}{rrr}
1 & -\frac{1}{2} & -\frac{1}{2} \\
0 & \frac{\sqrt{3}}{2} & -\frac{\sqrt{3}}{2}
\end{array}\right) \cdot U_{n}^{t}(k) \cdot\left(\begin{array}{rrr}
1 & -\frac{1}{2} & -\frac{1}{2} \\
0 & \frac{\sqrt{3}}{2} & -\frac{\sqrt{3}}{2}
\end{array}\right)
$$

\subsubsection{Cost Function}

A cost function is used to determine which configuration must be applied. As the main goal of the control scheme is to control output currents, a first cost function is proposed as the sum of differences between the reference currents $\mathrm{I}_{\mathrm{d}}^{\#}, \mathrm{I}_{\mathrm{q}}^{\#}$ and the predicted currents (21).

$$
G_{n}^{\prime}=I_{d}^{\#}-I_{d n}(k+1)|+| I_{q}^{\#}-I_{q n}(k+1)|+c .| \sin \left(\phi_{i n}(k+1)\right) \mid
$$

With this cost function, only output currents are controlled. However the matrix converter structure also allows to control input power factor. So input currents are computed with (20) in order to compute the angle between input current vector and input voltage vector if the configuration $n$ is applied $\left(\varphi_{i n}\right)$. Then a third term is added in (21) to take into account input power factor and in order to make it as close to unity as possible (22). 


$$
G_{n}^{\prime}=I_{d}^{\#}-I_{d n}(k+1)|+| I_{q}^{\#}-I_{q n}(k+1)|+c .| \sin \left(\phi_{i n}(k+1)\right) \mid
$$

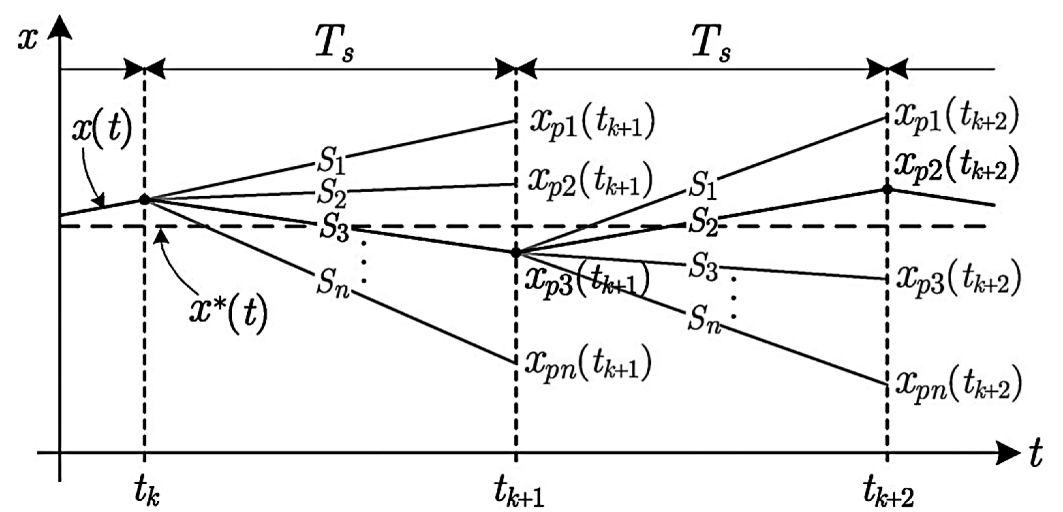

(a)

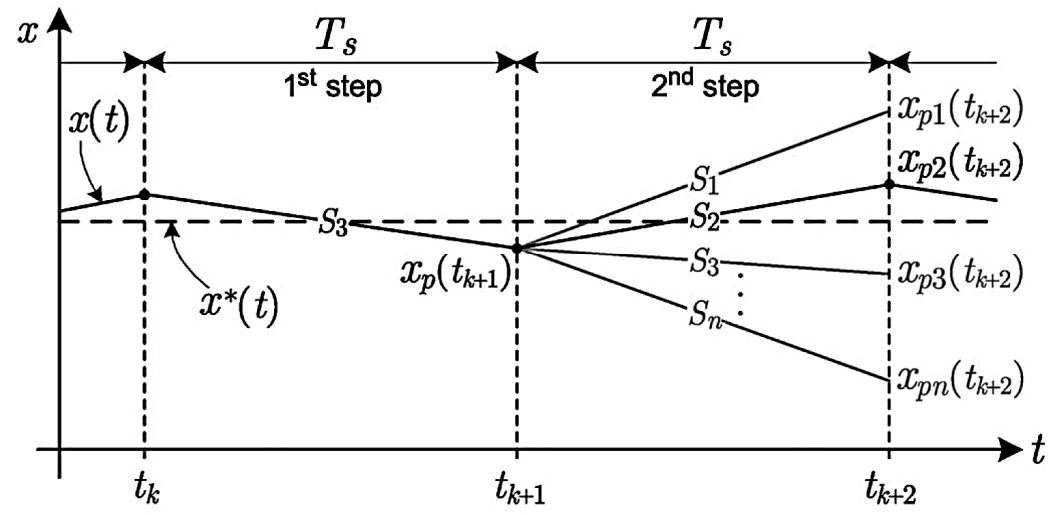

(b)

Fig.6. MPC operating principle. (a)Theoretical case. (b) Implementation case

In (22) $c$ is a weighting factor. Actually the instantaneous angle between input current vector and input voltage vector is used as a way to act on input power factor. With $c$, it is possible to obtain a trade-off between output current control and input power factor controls.

\section{BRANCH AND BOUND ALGORITHM FOR MPC}

The Prediction of future behaviour is not very simple from computational cost point of view. It becomes really complex when prediction is to be made for few samples. The B\&B approach [17] is based on the total set of feasible solutions that can be partitioned into subset of solutions which are estimated to get the finest solution [24]. Bounding value is the maximum cost at which the particular solution will be discarded and should not be branched further. Branch and bound scheme reduces the computational cost in three ways:

- Previous switching position of the MC is considered as the root node which is further branched to its eight possible positions. Then each of the eight possible switching positions 
is to be further branched to next eight possible positions. But using the branch and bound algorithm, if any switching position at first level is found to be unfeasible, it is not branched i.e.it has reached the allowable bound so that node will not be further branched. One particular case is explained in Fig. 7. Here the minimum size of $\mathrm{N}$ is 2 . The root node is $\{11$ $0\}$. Suppose that four nodes at first level $\left\{\begin{array}{lll}10 & 0\end{array}\right\},\left\{\begin{array}{lll}0 & 1 & 1\end{array}\right\},\left\{\begin{array}{lll}0 & 0 & 1\end{array}\right\}$ and $\left\{\begin{array}{lll}1 & 0 & 1\end{array}\right\}$ are not feasible due to violating either torque or flux limits. So these switching positions are not further branched. It saves computational efforts at level 2 and next levels if $\mathrm{N}$ is greater than 2 .

- If at stage during the scan, a sequence is found with minimum cost, the scanning process is stopped and that sequence is decided as the most suitable one.

- Before enumerating any node, the minimum possible cost of its child node sequences is calculated from maximum switching sequence length. It is compared with minimum cost obtained so far. If it is greater than the minimum cost till that stage, that particular node is discarded.

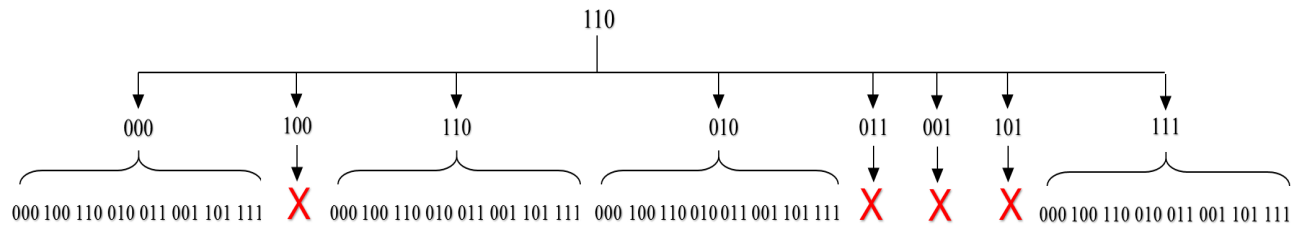

Fig.7. An Example of Branch \& Bound

\section{FLOW ChART OF MPC Algorithm}

The flowchart for the proposed MPC methodology is derived as per the Branch and Bound Algorithm and it is illustrated in the fig. 8 


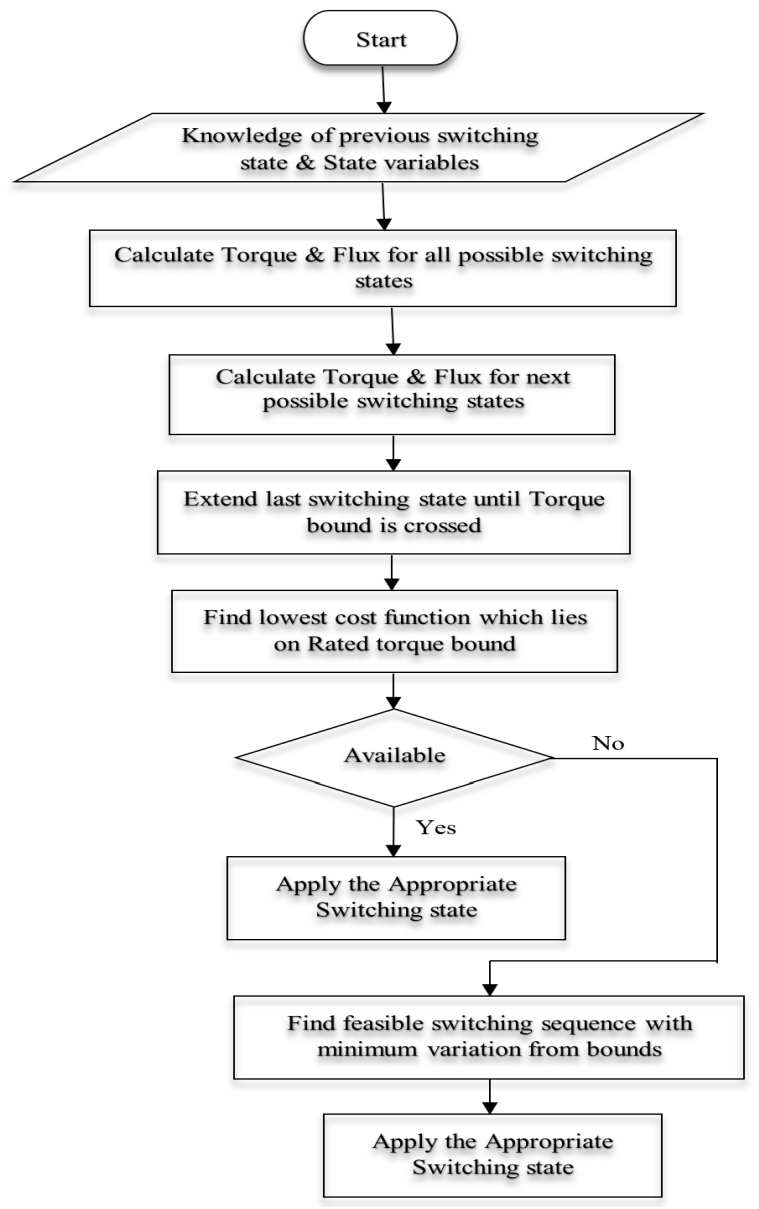

Fig.8. Flow Chart of Proposed MPC - Branch \& Bound Algorithm

\section{SimULATION RESULT}

The Simulation studies are carried out in MATLAB/Simulink to validate the proposed MC-DTC scheme for a $600 \mathrm{~W}$ PMSM drive system. The considerations of the PMSM are given as follows. The rated power is $600 \mathrm{~W}$;maximum speed is $3000 \mathrm{RPM} ; R_{s}=0.165 \Omega ; L_{d}=0.268 \mathrm{mH} ; L_{q}=$ $0.342 \mathrm{mH}$; the voltage constant $K_{e}=8.7 \mathrm{~V} / \mathrm{kRPM}$; the number of pole pairs is $p=4$; and the momentum of inertia is $J=0.000008 \mathrm{~kg} \cdot \mathrm{m}^{2}$. The switching frequency of MC-SVM scheme is 10 $\mathrm{kHz}$, which is typically used in practical motor drive systems. The Simulink diagram is shown in fig.9. Firstly, at $0 \mathrm{sec}$. the PMSM is operated at $10 \mathrm{Nm}$ Load Torque and then sudden changes of $15 \mathrm{Nm}, 20 \mathrm{Nm}$ and $5 \mathrm{Nm}$ are applied at $0.5 \mathrm{sec}, 1 \mathrm{sec}$ and $1.5 \mathrm{sec}$ respectively. The steady-state performances of the proposed MC-DTC are shown in fig.10. Moreover, the proposed DTC can output a larger mean torque at the same operating condition, which is important for drive systems 
International Journal of Soft Computing, Mathematics and Control (IJSCMC), Vol. 3, No. 4, November 2014

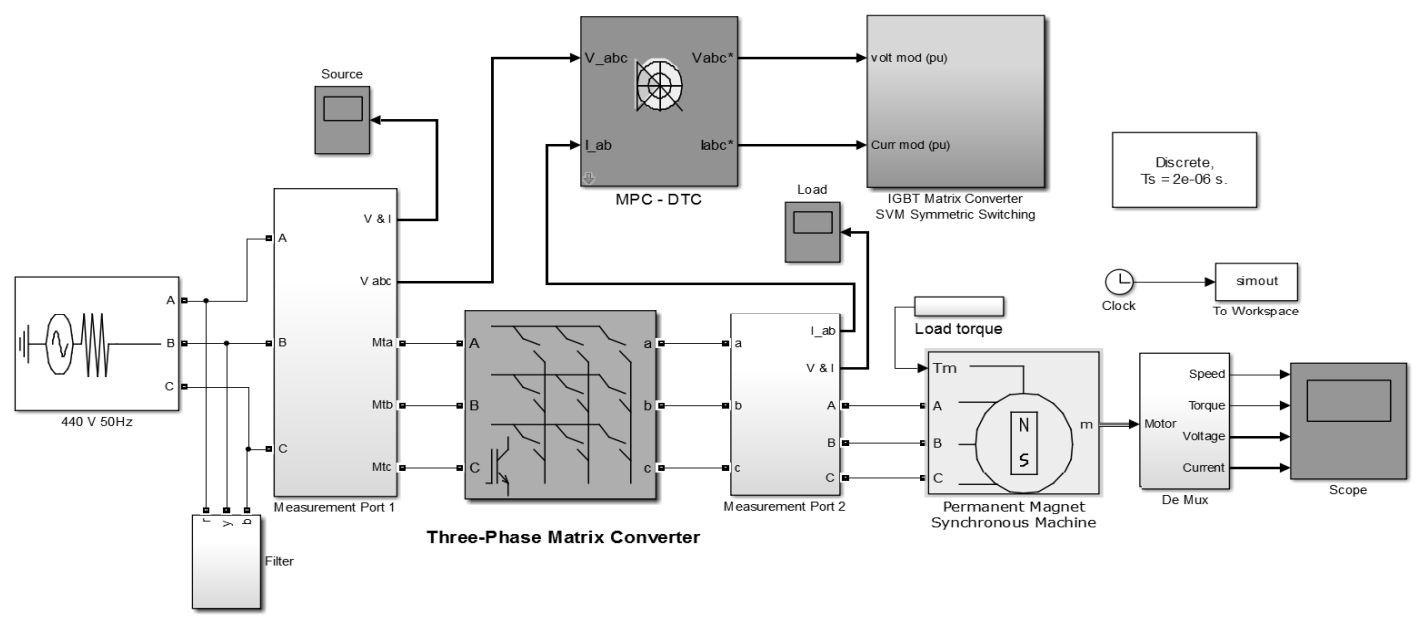

Fig. 9 . Simulink Diagram of Proposed MC-DTC

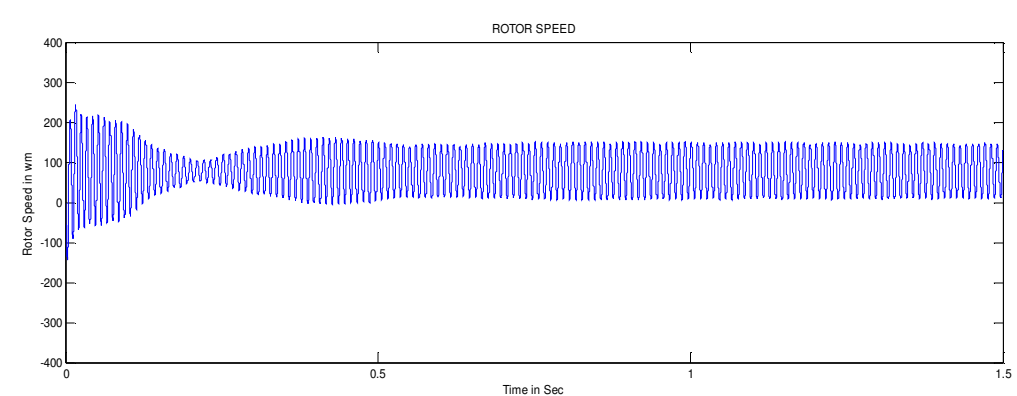

(a)

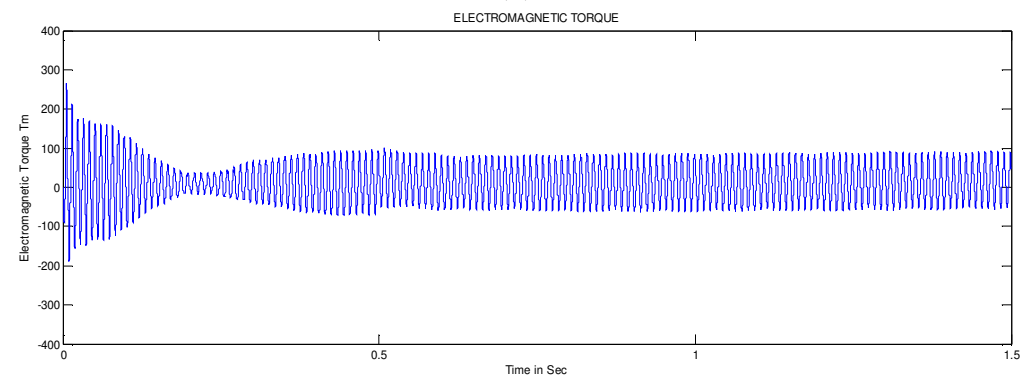

(b)

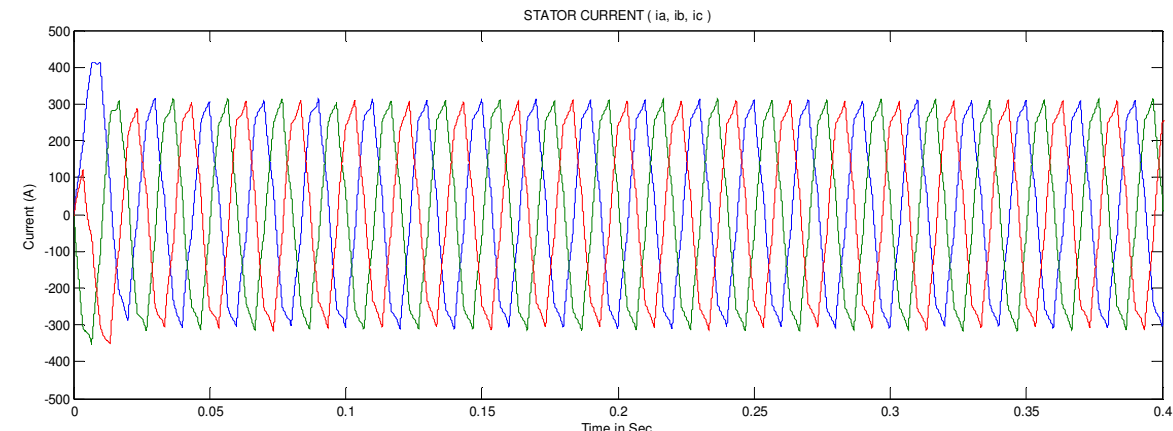

(c)

Fig.10.Steady state response.(a)Rotor speed,(b)Electromagnetic Torque, (c) Stator current $i_{a} \& i_{b}$ 


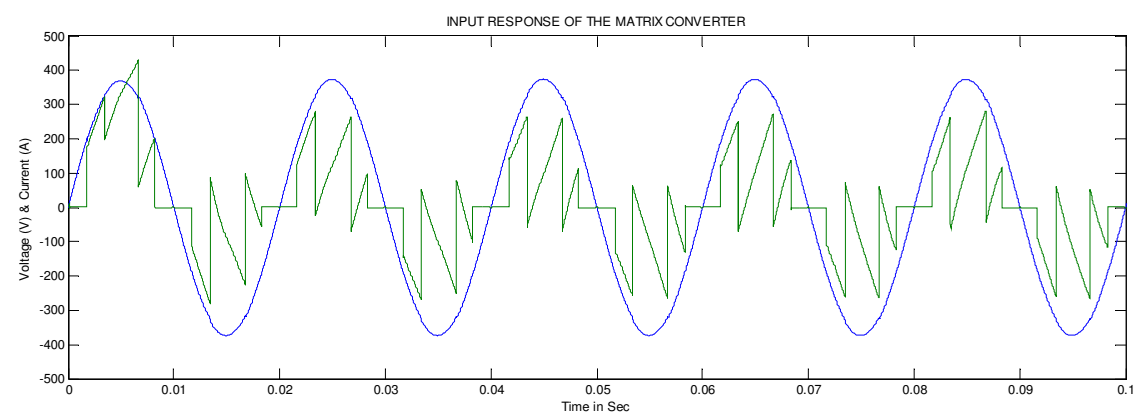

(a)

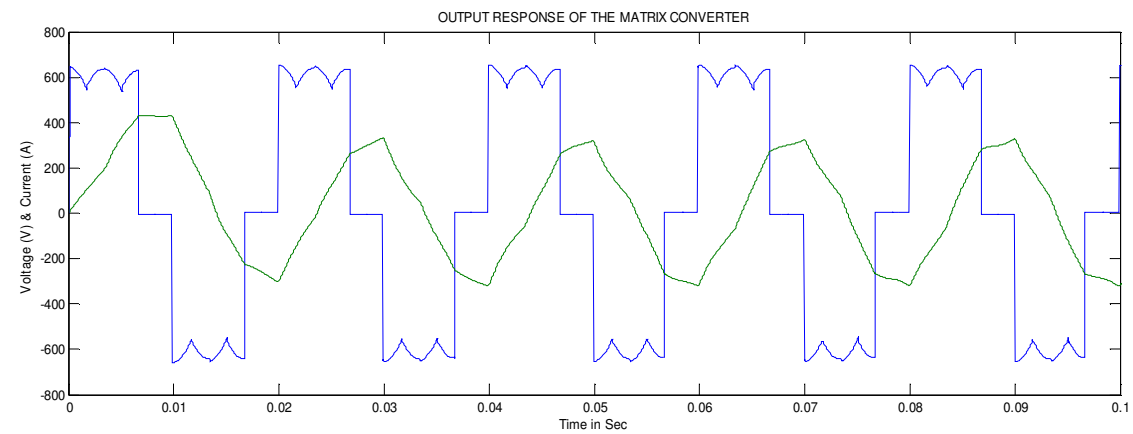

(b)

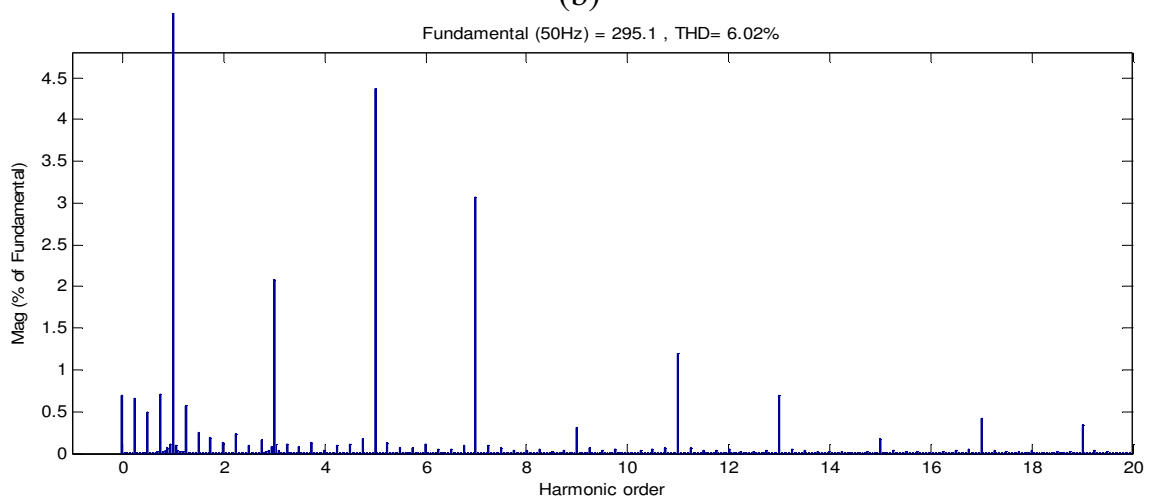

(c)

Fig.11. Steady state response. (a)Input Voltage \& Current,(b) Output Voltage \& Current, (c) THD analysis of MC current

\section{Conclusion And Future Work}

In this paper, an advanced DTC scheme for MC fed PMSM has been introduced. The method retains advantages inherited from the conventional Enhanced table- Duty cycle estimation technique of DTC, and decreases the torque ripples with the help of MPC algorithm by employing Branch and Bound method. This method is more direct and able to adopt with online estimation. In the future, this control method will be improved by deriving more accurate algorithm, in order to reach a milestone by which the torque ripple can be reduced fairly. 
International Journal of Soft Computing, Mathematics and Control (IJSCMC), Vol. 3, No. 4, November 2014

\section{REFERENCES}

[1] H. She, H. Lin, B. He, X. Wang, L. Yue, and X. An, "Implementation of voltage-based commutation in space-vector-modulated matrix converter," IEEE Trans. Ind. Electron., vol. 59, no. 1, pp. 154-166, Jan. 2012.

[2] C. Xia, P. Song, T. Shi, and Y. Yan, "Chaotic dynamics characteristic analysis for matrix converter," IEEE Trans. Ind. Electron., vol. 60, no. 1, pp. 78-87, Jan. 2013.

[3] J. Rodriguez, M. Rivera, J. Kolar, and P. Wheeler, "A review of control and modulation methods for matrix converters," IEEE Trans. Ind. Electron., vol. 59, no. 1, pp. 58-70, Jan. 2012.

[4] M. Venturini, "A new sine wave in sine wave out, conversion technique which eliminates reactive elements," in Proc. Powercon 7, 1980, pp. E3/1-E3/15.

[5] X. Wang, H. Lin, H. She, and B. Feng, "A research on space vector modulation strategy for matrix converter under abnormal input-voltage conditions," IEEE Trans. Ind. Electron., vol. 59, no. 1, pp. 93-104, Jan. 2012.

[6] M. Rivera, A. Wilson, C. A. Rojas, J. Rodriguez, J. R. Espinoza, P. W. Wheeler, and L. Empringham, "A comparative assessment of model predictive current control and space vector modulation in a direct matrix converter," IEEE Trans. Ind. Electron., vol. 60, no. 2, pp. 578-588, Feb. 2013.

[7] S. Kouro, P. Cortes, R. Vargas, U. Ammann, and J. Rodriguez, "Model predictive control, a simple and powerful method to control power converters," IEEE Trans. Ind. Electron., vol. 56, no. 6, pp. 1826-1838, Jun. 2009.

[8] D. Casadei, G. Serra, and A. Tani, "The use of matrix converters in direct torque control of induction machines,” IEEE Trans. Ind. Electron., vol. 48, no. 6, pp. 1057-1064, Dec. 2001.

[9] C. Ortega, A. Arias, C. Caruana, J. Balcells, and G. Asher, "Improved waveform quality in the direct torque control of matrix-converter-fed PMSM drives,” IEEE Trans. Ind. Electron., vol. 57, no. 6, pp. 2101-2110, Jun. 2010.

[10] K.-B. Lee and F. Blaabjerg, "Sensorless DTC-SVM for induction motor driven by a matrix converter using a parameter estimation strategy," IEEE Trans. Ind. Electron., vol. 55, no. 2, pp. 512-521, Feb. 2008.

[11] J. Wang and J. Jiang, "Variable-structure direct torque control for induction motor driven by a matrix converter with over modulation strategy," in Proc. 6th IEEE IPEMC, May 2009, pp. 580-584.

[12] D. Xiao and M. F. Rahman, "Sensorless direct torque and flux controlled IPM synchronous machine fed by matrix converter over a wide speed range,” IEEE Trans. Ind. Informat., vol. 9, no. 4, pp. 18551867, Nov. 2013.

[13] E. Yamamoto, H. Hara, T. Uchino, M. Kawaji, T. J. Kume, J.-K. Kang, and H.-P. Krug, "Development of MCs and its applications in industry," IEEE Ind. Electron. Mag., vol. 5, no. 1, pp. 4-12, Mar. 2011.

[14] G. S. Buja and M. P. Kazmierkowski, "Direct torque control of PWM inverter-fed ac motors-A survey,” IEEE Trans. Ind. Electron., vol. 51, no. 4, pp. 744-757, Aug. 2004.

[15] C.Xia, J.Zhao, Y.Yan, and T.Shi , "A Novel Direct Torque Control of Matrix Converter-Fed PMSM Drives Using Duty Cycle Control for Torque Ripple Reduction,” IEEE Trans.Ind.Electron, vol. 61, no. 6, pp. 2700-2713, Jun. 2014.

[16] T.Geyer, and G.Papafotiou, "Model Predictive Direct Torque Control of a Variable Speed Drive with a Five-Level Inverter", IEEE Industrial Electronics, 35th Annual Conference, pp.1203-1208, Nov. 2009

[17] M. A. Naeem, and K. M. Hasan , "Direct Torque Control (DTC) of Three Phase Induction Motor using Model based Predictive Control (MPC) scheme deploying Branch and Bound Algorithm", ICRERA 2013, Madrid, Spain, Oct. 2013

[18] I. Takahashi and T. Noguchi, "A new quick response and high efficiency control strategy for an induction motor,” IEEE Trans. Ind. Electron., vol. IE-22, no. 5, pp. 820-827, Sep. 1986.

[19] J. Zhoua and Y. Wang, "Real-time nonlinear adaptive back stepping speed control for a PM synchronous motor," Control Eng. Pract., vol. 13, pp. 1259- 1269, 2005.

[20] L. Zhong, M. Rahman, W. Hu, and K. Lim, "Analysis of direct torque control in permanent magnet synchronous motor drives," IEEE Trans. Power Electron., vol. 12, no. 3, pp. 528-536, May 1997.

[21] C. E. Garcia, D. M. Prett, and M. Morari, "Model predictive control: Theory and practice - a survey," Automatica, vol. 25, no. 3, pp. 335-348, Mar. 1989. 
[22] M.Fan, H.Lin , and T.Lan , "Model Predictive Direct Torque Control for SPMSM with Load Angle Limitation", Progress In Electromagnetics Research B, Vol. 58, 245 -256, Mar.2014

[23] M. Pacas and J. Weber, "Predictive direct torque control for the PM synchronous machine," IEEE Trans. Ind. Electron., vol. 52, no. 5, pp. 1350-1356, Oct. 2005.

[24] T. Geyer, "Low complexity model predictive control in power electronics and power systems," Ph.D. dissertation, Automatic Control Laboratory ETH Zurich, 2005.

\section{Authors}

Mr.S.Kannan , He completed his B.E in Electrical and Electronics Engineering from Sasurie College of Engineering, Tirupur, India and currently doing M.E in K.S.R. College of Engineering ,Tiruchengode, India. He worked as a Lecturer in M.Kumarasamy College of Engineering, Karur, India for 2 years. His area of interest includes Electrical Machines, Power Electronics \& Soft computing Techniques.

Mr.S.Chinnaiya, He completed his M.E in Power Electronics and Drives from Anna University, Chennai, India and pursuing Ph.D under Anna University, Chennai. He is a lifetime member in ISTE. At present he is working as an Assistant Professor in EEE Department at KSR College of Engineering, Tiruchengode, India. His area of interest includes Matrix Converter, Power Quality, and Intelligent Controllers.

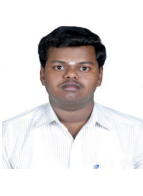

Dr.S.U.Prabha, She completed her M.E. in Electrical Machines from Bharathiar University, Coimbatore, India and her Ph.D in Power Systems from Multimedia University, Malaysia. She is a lifetime member in ISTE and also a member of IEEE. At present she is working as a Professor and Head in EEE Department at Sri Ramakrishna Engineering College, Coimbatore,

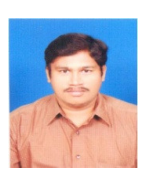
India. She is a reviewer for various International Journals. She has published more than 20 research papers in various International Journals and Conferences. Her areas of interest are Power Systems and Electrial Machines. 